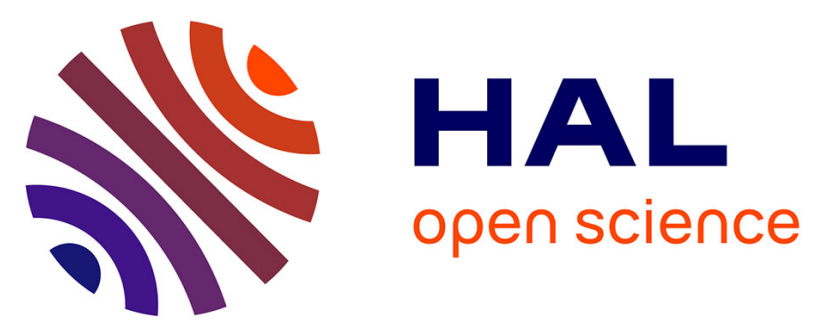

\title{
Development of an improved falling ball viscometer for high-pressure measurements with supercritical CO2
}

Brice Calvignac, Élisabeth Rodier, Jean-jacques Letourneau, Pauline Vitoux, Cyril Aymonier, Jacques Fages

\section{To cite this version:}

Brice Calvignac, Élisabeth Rodier, Jean-jacques Letourneau, Pauline Vitoux, Cyril Aymonier, et al.. Development of an improved falling ball viscometer for high-pressure measurements with supercritical CO2. Journal of Supercritical Fluids, 2010, 55 (1), pp.96-106. 10.1016/j.supflu.2010.07.012 . hal00545053

\section{HAL Id: hal-00545053 \\ https://hal.science/hal-00545053}

Submitted on 22 Nov 2017

HAL is a multi-disciplinary open access archive for the deposit and dissemination of scientific research documents, whether they are published or not. The documents may come from teaching and research institutions in France or abroad, or from public or private research centers.
L'archive ouverte pluridisciplinaire HAL, est destinée au dépôt et à la diffusion de documents scientifiques de niveau recherche, publiés ou non, émanant des établissements d'enseignement et de recherche français ou étrangers, des laboratoires publics ou privés. 


\title{
Development of an improved falling ball viscometer for high-pressure measurements with supercritical $\mathrm{CO}_{2}$
}

\author{
Brice Calvignac $^{\mathrm{a}, \mathrm{b}, *}$, Elisabeth Rodier ${ }^{\mathrm{a}, \mathrm{b}}$, Jean-Jacques Letourneau ${ }^{\mathrm{a}, \mathrm{b}}$, Pauline Vitoux ${ }^{\mathrm{c}}$, \\ Cyril Aymonier ${ }^{\mathrm{c}}$, Jacques Fages ${ }^{\mathrm{a}, \mathrm{b}}$ \\ ${ }^{a}$ Ecole des Mines Albi, Centre RAPSODEE, F-81013 Albi, France \\ ${ }^{\mathrm{b}}$ Université de Toulouse, Mines Albi, CNRS, F-81013 Albi, France \\ ${ }^{c}$ CNRS, Université de Bordeaux, ICMCB, 87 Av. du Dr A. Schweitzer, F-33608 Pessac, France
}

\begin{abstract}
This study presents the development of an improved technique for viscosity measurements under high pressure. The apparatus is based on the principle of the falling ball viscometer, implemented in a highpressure autoclave fitted with visualisation windows. The originality here is that the balls fall through a tube open at both ends with a diameter slightly greater than that of the balls, allowing a simplified modelling and numerical simulation. A numerical approach has been used for viscosity determination. Calculations have been made with COMSOL Multiphysics ${ }^{\circledR}$ with the laminar Navier-Stokes model for Newtonian mixtures. It includes the specific hydrodynamic effects without the need for a calibration fluid. However, validation experiments were carried out at atmospheric pressure with dimethylsulfoxide (DMSO) at 298, 308 and $318 \mathrm{~K}$ and with cocoa butter at 313 and $353 \mathrm{~K}$, with values of viscosity in the range from 1.4 to $45.4 \mathrm{mPa}$. Comparative measurements with literature data have been conducted with cocoa butter saturated with carbon dioxide at 313 and $353 \mathrm{~K}$ and for pressures ranging from 0.1 to $25 \mathrm{MPa}$. At $313 \mathrm{~K}$, viscosity varies from $45.4 \mathrm{mPa}$ s to $3.1 \mathrm{mPa}$ s while at $353 \mathrm{~K}$ it varies from 12.4 to $1.9 \mathrm{mPa}$. For both isotherms tested, within the range $0-15 \mathrm{MPa}$, the higher the $\mathrm{CO}_{2}$ dissolution in the cocoa butter, the lower the viscosity. However, this decrease in viscosity is more pronounced at the lowest temperature. Above $15 \mathrm{MPa}$ the $\mathrm{CO}_{2}$ dissolution effect on viscosity becomes insignificant, i.e. within the experimental error, due to a counter effect linked with the high hydrostatic pressure. Furthermore, the limits of use of this method have been determined. This technique is revealed as reliable and can therefore be used with other binary systems.
\end{abstract}

\section{Introduction}

Supercritical fluid processes are clean and efficient alternatives to conventional methods in several fields such as extraction, crystallization, chromatography and material processing [1]. Supercritical carbon dioxide $\left(\mathrm{scCO}_{2}\right)$ is often selected as a solvent for food and pharmaceuticals processing. As a matter of fact, knowledge of physical properties of binary mixtures over an extended range of temperatures and pressures is essential for process design. This can often require the development or the modification of characterization techniques and a previous work focussed on measurement and modelling of thermodynamical properties such as solubility has already been published $[2,3]$. It has been extended

\footnotetext{
* Corresponding author at: Ecole des Mines Albi, Centre RAPSODEE, F-81013 Albi, France. Tel.: +335634930 07; fax: +33563493025.

E-mail address: brice.calvignac@mines-albi.fr (B. Calvignac).
}

to other types of properties such as transport. For instance, the viscosity of fluid mixtures is also required to determine pressure drops in piping systems [4], to understand the molecular interactions in separation processes involving heat and mass transfer such as extraction and fractionation of biomaterials. The viscosity of a material is again needed for the design and optimization of polymer processes such as extrusion [5], foaming [6,7], synthesis reactions [8] and gas-assisted injection moulding [9]. In all applications, the addition of a miscible dense fluid such as $\mathrm{scCO}_{2}$ will tend to enhance transport properties. Various methods can be used to measure the viscosity of fluids under high pressure: capillary [10,11], vibrating wire [12], quartz [13], rotational [14] and falling body [15-25] viscometers. The latter have been used to measure the high-pressure viscosity of hydrocarbons $[15,16]$, oils $[17,18]$ and binaries composed of $\mathrm{CO}_{2}$ and polymer solutions [19-21] or organic solvents [22-25]. Various shapes and sizes of falling body could be used, such as a needle, a cylinder or a sphere, chosen because of the simplicity of the viscosity calculations. A hard sphere, initially at rest 


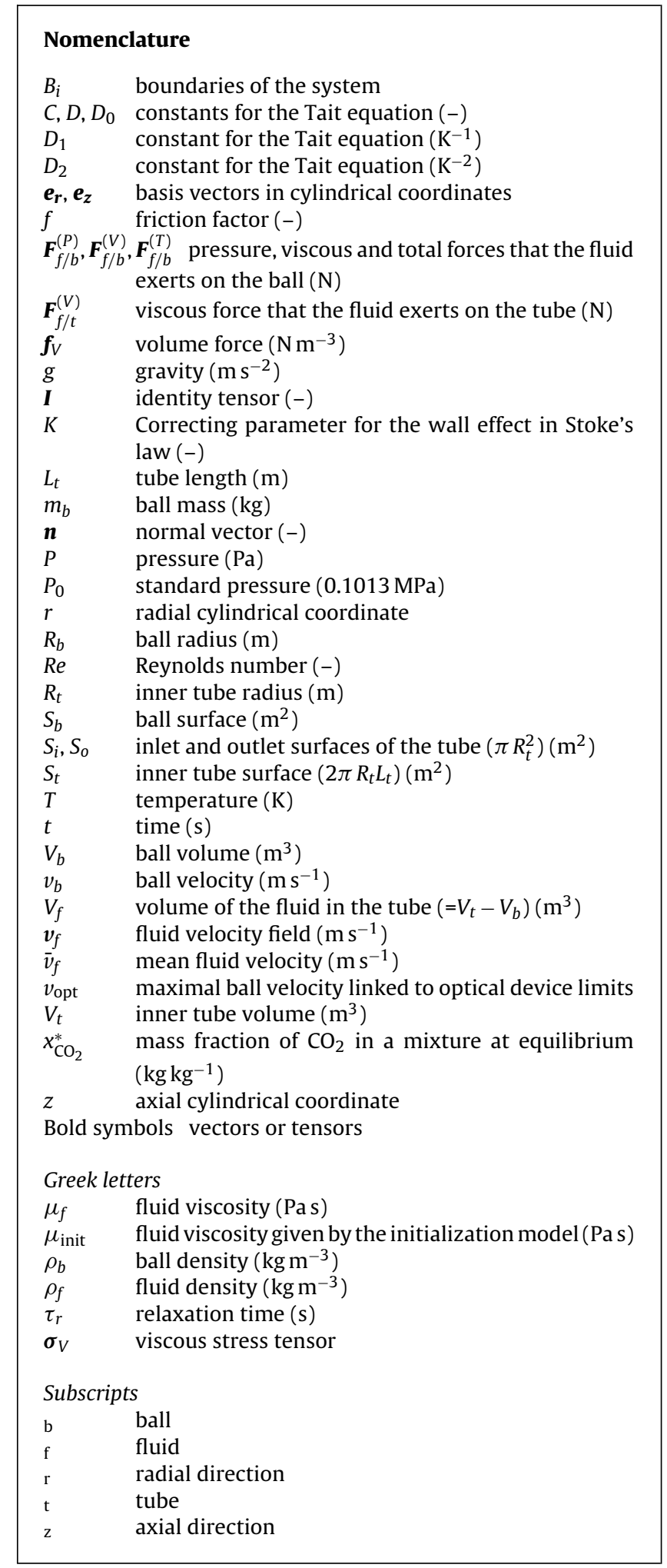

and falling in a tube filled with fluid is often considered. The sphere (or ball) accelerates until it reaches a constant velocity, named terminal velocity, when the drag and buoyant forces exerted on the sphere balance the gravitational force. Assuming that the fluid is Newtonian and incompressible, and that the flow is stationary, laminar and axial symmetric, the fluid viscosity, $\mu_{f}$ is given by Stokes'
Table 1

\begin{tabular}{lc} 
Composition in triglycerides (TG) of cocoa butter. \\
\hline TG & Weight fraction (\%) \\
\hline OLO & 0.4 \\
PLP & 0.4 \\
OOO & 1.5 \\
POO & 0.3 \\
PLS & 1.8 \\
POP & 18.0 \\
POS & 38.3 \\
SOS & 26.0 \\
SOO & 1.8 \\
SLS & 2.4 \\
PPS & 4.7 \\
PSS & 3.1 \\
SOA & 1.1 \\
SSS & 0.3 \\
\hline
\end{tabular}

law according:

$\mu_{f}=K \frac{2 R_{b}^{2} g\left(\rho_{b}-\rho_{f}\right)}{9 v_{b}}$

where $v_{b}$ is the ball velocity, $R_{b}$ is the ball radius, $\mu_{f}$ is the fluid viscosity, and $\rho_{f}$ and $\rho_{b}$ are the fluid and ball densities, respectively. Eq. (1) is a modified Stokes' law where $K$ is an empirical parameter that takes into account the wall and end effects. Usually, it is determined experimentally for a given temperature with a fluid for which the viscosity is well referenced. Several authors $[26,27]$ have proposed semi-empirical correlations for this correction factor.

In this paper, an improved high-pressure falling ball viscometer is described. This includes a presentation of the apparatus, of the image analysis treatment, which gives the terminal velocity value, of the modelling of a falling ball inside this viscometer and of the simulation using Comsol Multiphysics ${ }^{\circledR}$ software. The latter gives the value of the mixture viscosity corresponding to the terminal velocity measured.

The objective here is to give as complete as possible an overview of this viscosity measurement method, including its experimental and modelling aspects, validation results at atmospheric pressure, its application to a $\mathrm{CO}_{2}$-saturated mixture, its assets and its limitations. Viscosity determination under atmospheric pressure was performed for an organic solvent, dimethylsulfoxide (DMSO), and for a natural product, cocoa butter. The $\mathrm{CO}_{2}$-saturated mixture was based on cocoa butter.

\section{Experimental}

\subsection{Materials}

DMSO (purity 99\%, w/w) was obtained from Fluka (Buchs, Switzerland). Because of its hygroscopic nature, a 1-h drying step, under vacuum, was carried out in the characterization device itself, before each experiment. Carbon dioxide (purity 99.995\%, w/w) was purchased from Air liquide S.A. (Paris, France). Cocoa butter (CB) was obtained from Gerkens Cacao B.V. (Wormer, The Netherlands). Cocoa butter, the fat of chocolate, is a complex natural product composed of different types of triglycerides (TG) whose proportions vary according to its origin. The total mass fraction of TG is usually around $98 \%$ whatever the origin. The TG composition of the $\mathrm{CB}$ used here is given in Table 1. It was measured by HPLC using a column Spherisorb 80 ODS2, $250 \mathrm{~mm} \times 4.6 \mathrm{~mm}$, set at $313.15 \mathrm{~K}$ and a refraction index detector. The mobile phase was a mixture of acetone and acetonitrile in isocratic conditions, ratio $1: 1$, eluted at a flowrate of $1 \mathrm{~cm}^{3} / \mathrm{min}$. 


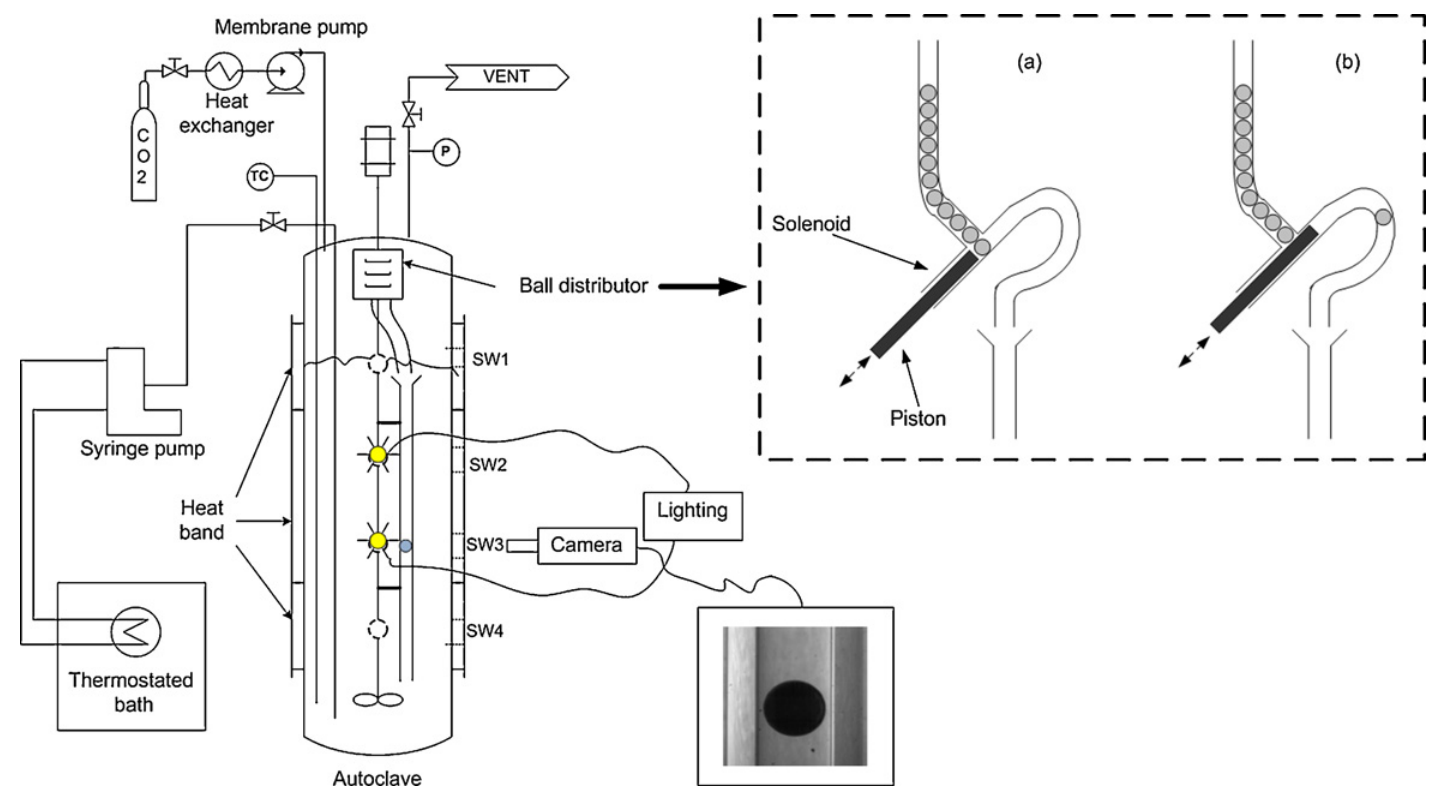

Fig. 1. Scheme of the high pressure falling ball viscometer.

\subsection{Experimental set-up and procedure}

A schematic diagram of the viscometer is shown in Fig. 1. The apparatus has been designed to carry out investigations under pressures and temperatures up to respectively $44 \mathrm{MPa}$ and $473.15 \mathrm{~K}$. The stainless steel autoclave with a capacity of $2.6 \mathrm{dm}^{3}$ (Top-Industrie, Vaux le-Pénil, France) is previously loaded with approximately $1.5-2 \mathrm{dm}^{3}$ of liquid phase, e.g. melted CB or DMSO, and heated to the desired temperature. It is equipped with eight sapphire windows (SW), $20 \mathrm{~mm}$ diameter, for visualization purpose using a cold lighting device (model CLS150X, Leica Microsystems, Wetzlar, Germany) and a high-speed digital video camera (model Fastcam PCIR2, Photron, San Diego, USA) connected to a computer. Liquid $\mathrm{CO}_{2}$ is pumped with a high-pressure membrane pump (Lewa, Sartrouville, France) and preheated by a heat exchanger (Separex, Champigneulles, France) before flowing into a stirred autoclave. The axis of the magnetic stirrer is equipped with six $45^{\circ}$-inclined blades, $45 \mathrm{~mm}$ diameter (Top-Industrie, Vaux-le-Pénil, France), and the stirring speed is $800 \mathrm{rpm}$. Then, a syringe pump (Model ISCO 100HLX, Teledyne Isco, Inc, Lincoln, USA) previously filled with the liquid phase, melted CB or DMSO, is connected to the autoclave and is maintained at the same temperature than the mixture in the autoclave. Upon dissolution of supercritical $\mathrm{CO}_{2}$, the liquid phase expands and the liquid level increases. The syringe pump is then used to immerse totally the glass tube. To adjust the fluid level without overfilling the autoclave, small amounts of liquid phase can be withdrawn (or added) by the syringe pump. The pressure and temperature inside the viscometer are kept constant within $\pm 0.1 \mathrm{MPa}$ and $\pm 0.10 \mathrm{~K}$. During all these steps, the fluid is stirred in order to enhance the mass transfer and to speed up the saturation of the liquid phase. Once the equilibrium is reached, $24 \mathrm{~h}$ later, stirring is stopped and viscosity measurements can be performed. During these measurements, pressure and temperature are kept constant.

Measurements consist in recording through a sapphire window (SW3) the fall of an aluminium ball $(2.0000 \pm 0.0005 \mathrm{~mm}$ diameter at $298.15 \mathrm{~K}$, Valette \& Gaurand Industrie, La Talaudière, France) through the glass tube open at both ends $(2.10 \pm 0.01 \mathrm{~mm}$ inner diameter at $298.15 \mathrm{~K}, 200 \mathrm{~mm}$ length, Verres Wagner, Toulouse, France). Although the rugosity of the inner tube surface has not been determined, the optical quality of the glass ensures a smooth enough surface. The dilatation effects have been calculated using Comsol Multiphysics ${ }^{\circledR}$ on the basis of the linear thermal expansion coefficient for aluminium and optical glass, in the range $298.15-353.15 \mathrm{~K}$. The resulting tube inner radius decrease is $41 \mathrm{~nm}$ and the ball radius increase is $1.27 \mu \mathrm{m}$. These effects have then been neglected. However, another ball material such as quartz or ruby could have been a better choice, with a ball dilatation being fifty times lower. But the size tolerance of the corresponding available balls is greater than the dilatation effect of aluminium. As for the glass tube, it is fastened to a metal rod fixed to the top of the autoclave and its position is adjusted by means of micrometer screws. It has been previously levelled by means of a plumb line inserted through the tube. The verticality has been checked before and after each experiment.

The ball velocity is measured at the middle height of the tube. Following the time course of the ball position has showed that the speed is constant and therefore equals the falling terminal velocity. The density of the aluminium balls $\left(2723.3 \pm 0.9 \mathrm{~kg} \mathrm{~m}^{-3}\right)$ was previously determined with a helium pycnometer (model Accupyc 1330, Micromeritics, Verneuil-en-Halatte, France). Other materials for balls have been tested such as steel and a polymer, polyacetal. The use of a steel ball was inappropriate due to too high its density $\left(7800 \mathrm{~kg} \mathrm{~m}^{-3}\right)$. Due to diffusion of $\mathrm{CO}_{2}$ into polyacetal balls, this material could not be used either. The ball distributor (ball capacity: 60, home-made) releases single-use balls, one at a time, by means of an electrical impulsion applied to the solenoid (Fig. 1(a) and (b)). The ball release is manually induced and the first two balls are discarded because their role is simply to allow the evacuation of the fluid that may not be saturated. As the tube is open at both ends and the radius difference between the ball and the tube is only $50 \mu \mathrm{m}$, the fall of one or two balls is enough to replace all the internal fluid by the saturated mixture. Moreover, repeated velocity measurements have showed no variation suggesting that the fluid composition and density remained unchanged. Afterwards, at least five consecutive balls are released in order to perform five different terminal velocity measurements. A ball is released once the previous ball has reached the outlet of the glass tube. The reproducibility of the velocity measurement has then been checked.

The key features for the viscosity determination are the ball terminal velocity, the fluid density and the ball density. The ter- 


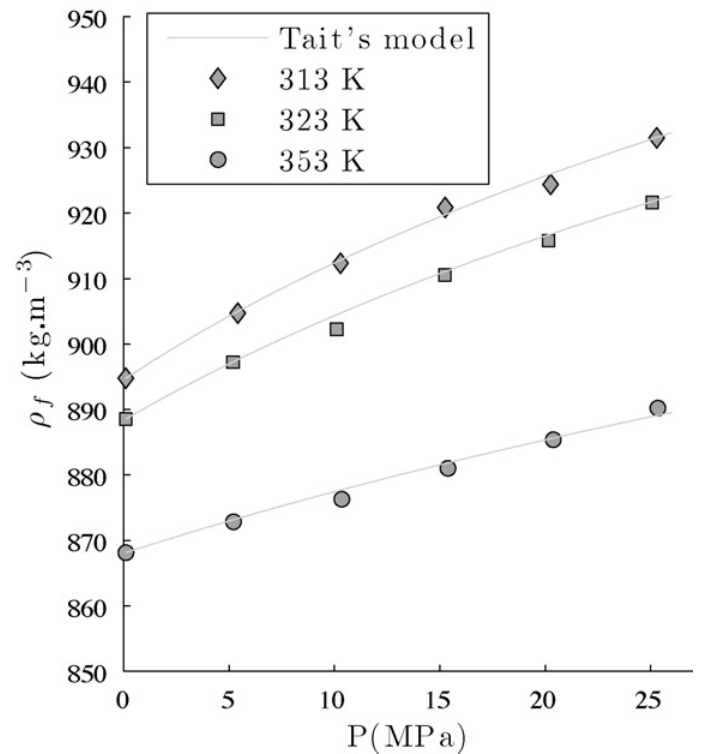

Fig. 2. Density of $\mathrm{CO}_{2}$-saturated cocoa butter $(\mathrm{CB})$ as a function of pressure

minal velocity values are obtained from the analysis of the images taken with a high-speed digital camera, using a software developed with the Image Processing Toolbox of Matlab ${ }^{\circledR}$. The fluid density has previously been measured with a vibrating U-tube densimeter (Model DMA-HPM, Anton-Paar, Graz, Austria). The experimental set-up and its calibration have been described in previous studies $[25,28]$. Density data of the cocoa butter saturated with $\mathrm{CO}_{2}$, which are needed for viscosity measurements at given pressure and temperature, have been interpolated using the empirical Tait equation [29]:

$\rho_{f}(T, P)=\rho_{f}\left(x_{\mathrm{CO}_{2}}^{*}(T, P), T, P\right)=\frac{\rho_{f}\left(T, P_{0}\right)}{1-C \ln \left(\frac{D(T)+P / P_{0}}{D(T)+1}\right)}$

with:

$D(T)=D_{0}+D_{1} T+D_{2} T^{2}$

where $\rho_{f}$ is the fluid density at given pressure and temperature. $D_{0}, D_{1}, D_{2}$ and $C$ are fitting parameters and are equal to 7915.5 , $-51.1 \mathrm{~K}^{-1}, 0.847 \mathrm{~K}^{-2}$ and 0.505 respectively. This empirical model has been used to fit experimental density of $\mathrm{CO}_{2}$-saturated cocoa butter which has been measured at $313.15,323.15$ and $353.15 \mathrm{~K}$ and for pressures ranging from 0.1 to $25 \mathrm{MPa}$ (Fig. 2).

\subsection{Viscosity calculation}

\subsubsection{Initialization model: a simplified model}

This model is based on theoretical considerations combined with simplification hypotheses. It allows the determination of an approximate value of the viscosity from the ball velocity and the fluid density.

While the ball is falling in the tube, it acts as a piston and the fluid flows through the top inlet boundary of the system and goes out through the bottom outlet boundary. Once the ball reaches its terminal velocity, a stationary flow for the fluid is established. The development of this model is presented in Appendix A. It leads to Eq. (4), which gives an analytical expression for the viscosity:

$\mu_{\text {init }}=\frac{1}{6} \frac{\left(\rho_{b}-\rho_{f}\right) g R_{b} R_{t}^{2}}{L_{t} v_{b}}$
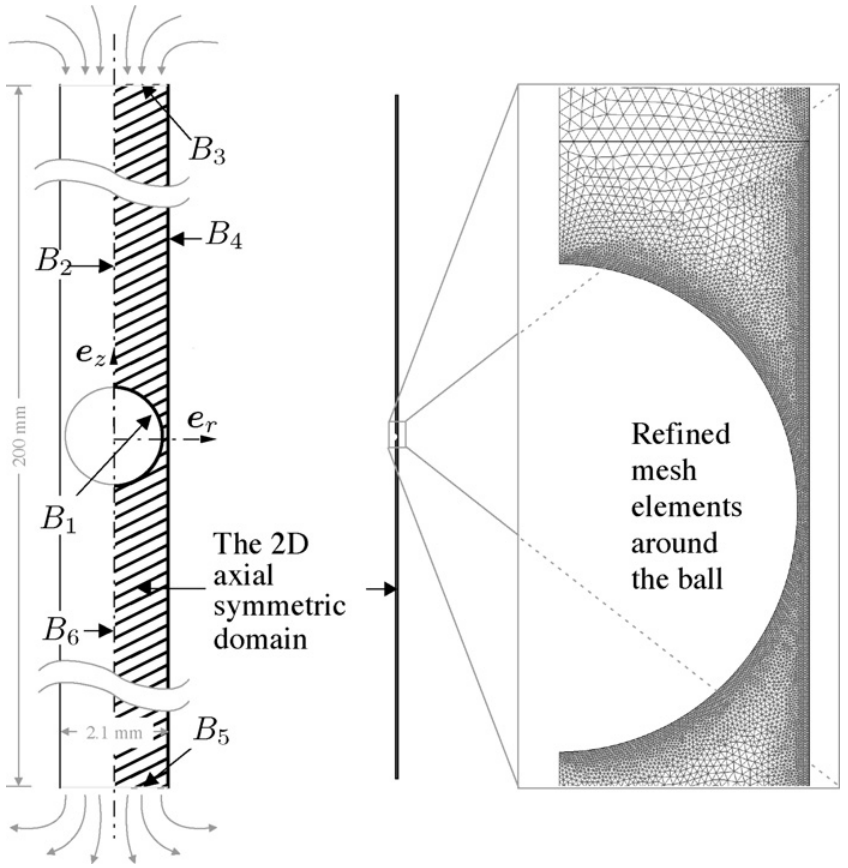

Fig. 3. The different boundaries of the system (hatched area) and details of the refined mesh for the CFD simulations.

This model does not account for wall effects: it does not matter here because it is only used to initialize numerical calculations that will lead to the precise value of the fluid viscosity $\mu_{f}$. In addition, the fluid viscosities calculated by Eq. (1) with $K=1$ (Stokes' law in infinite medium) and Eq. (4), are significantly different. For the same fluid viscosity, the ratio of the ball velocities calculated from Eq. (1) with $K=1$ and Eq. (4) is about 240, showing the relevance of using a confined flow implying very low Reynolds numbers. Therefore, the validity range for the model is guaranteed and low velocities permit to set-up visual techniques in a much easier way.

\subsubsection{Computational fluid dynamics (CFD) model}

The fluid flow in the tube has been modelled using the laminar Navier-Stokes model implemented in software Comsol Multiphysics ${ }^{\circledR}$ 3.4. CFD simulations have been carried out in the reference frame of the ball on the two-dimensional axial symmetric domain shown in Fig. 3, with $\boldsymbol{v}_{f}=0$ for $t=0$.

The partial differential equations (PDE) system in this twodimensional configuration includes the laminar Navier-Stokes equation for a Newtonian fluid and the continuity equation for an incompressible fluid:

$\left\{\begin{array}{l}\rho_{f} \frac{\partial \boldsymbol{v}_{f}}{\partial t}+\rho_{f}\left(\boldsymbol{v}_{f} \cdot \nabla\right) \boldsymbol{v}_{f}=\nabla \cdot\left(P \boldsymbol{I}+\boldsymbol{\sigma}_{V}\right)+\boldsymbol{f}_{V} \\ \nabla \cdot \boldsymbol{v}_{f}=0\end{array}\right.$

where $\boldsymbol{f}_{V}$ is the volume force exerted on the fluid, and where the viscous stress tensor has the following Newtonian expression:

$\sigma_{V}=\mu_{f}\left(\nabla v_{f}+\left(\nabla v_{f}\right)^{T}\right)$

The problem is solved in the accelerating reference frame of the ball. In this system the volume force is:

$\boldsymbol{f}_{V}=-\rho_{f} \frac{d v_{b}}{d t} \boldsymbol{e}_{z}-\rho_{f} g \boldsymbol{e}_{z}$ 
where $\frac{d v_{b}}{d t}$ is the acceleration of the ball, which is described according to:

$m_{b} \frac{d v_{b}}{d t}=\left(\boldsymbol{F}_{f / b}^{(T)}+m_{b} \mathbf{g}\right) \cdot \boldsymbol{e}_{z}$

with:

$\boldsymbol{F}_{f / b}^{(T)}=\boldsymbol{F}_{f / b}^{(P)}+\boldsymbol{F}_{f / b}^{(V)}$

where $\boldsymbol{F}_{f / b}^{(T)}$ is the total force (viscous force $\boldsymbol{F}_{f / b}^{(V)}$ plus pressure force $\left.\boldsymbol{F}_{f / b}^{(P)}\right)$ that the fluid exerts on the ball and is calculated by integrating the normal component of the stress tensor over the surface of the ball:

$\boldsymbol{F}_{f / b}^{(T)}=\int_{S_{b}}\left(-P \boldsymbol{I}+\boldsymbol{\sigma}_{V}\right) \cdot \boldsymbol{n} d S$

Boundaries are shown in Fig. 3. Boundary $B_{1}$ represents the ball surface on which there is a no-slip condition. Boundaries $B_{2}$ and $B_{6}$ correspond to the axial symmetry of the tube. Boundary $B_{3}$ is the tube inlet: it is an open boundary at a fixed pressure. Boundary $B_{5}$ is the tube outlet: it is an open boundary at a fixed pressure, equal to the pressure at $B_{3}$ increased by the hydrostatic pressure due to the height of the tube. Boundary $B_{4}$ corresponds to the inner surface of the tube: in the reference frame of the ball, this surface has a vertical velocity that is calculated at each time step by the integration of the ordinary differential Eq. (8).

The system, that is the hatched area in Fig. 3, has been meshed according to 15,000 triangular elements. Near the boundaries, especially near the ball, the mesh has been refined. The number of elements was increased until the results of the simulation remained unchanged.

This CFD model is based on the one presented in [30] except that the terminal ball velocity is known and the fluid viscosity is unknown. Therefore, for each CFD simulation, the initial value of the fluid viscosity was estimated by the initialization model value (see Appendix A) and self-adjusted with an iteration loop until the terminal ball velocity converges towards the measured value.

Due to the fact that the ball is taken into account in the geometry of the system and to the finite element method used here, all effects and especially wall effects are considered in the CFD calculation. This is the main difference between the initialization model and the CFD calculation, leading to the variations observed in the values of viscosity given by both methods.

\subsection{Validation of the experimental technique}

A well-defined binary mixture had to be selected in order to validate the technique. In addition, this work was part of a more extended study and this validation had to be simultaneously undertaken for other characterization techniques such as high-pressure density, $\mathrm{CO}_{2}$ solubility and volumetric expansion measurements [25]. From a literature survey, we selected a few potential candidates. Among them, $\mathrm{CO}_{2}$-DMSO mixture appeared to be the most appropriate because of its low toxicity, low volatility and because it was the most documented in literature. Moreover, the range of the above-cited properties was possible within the operating

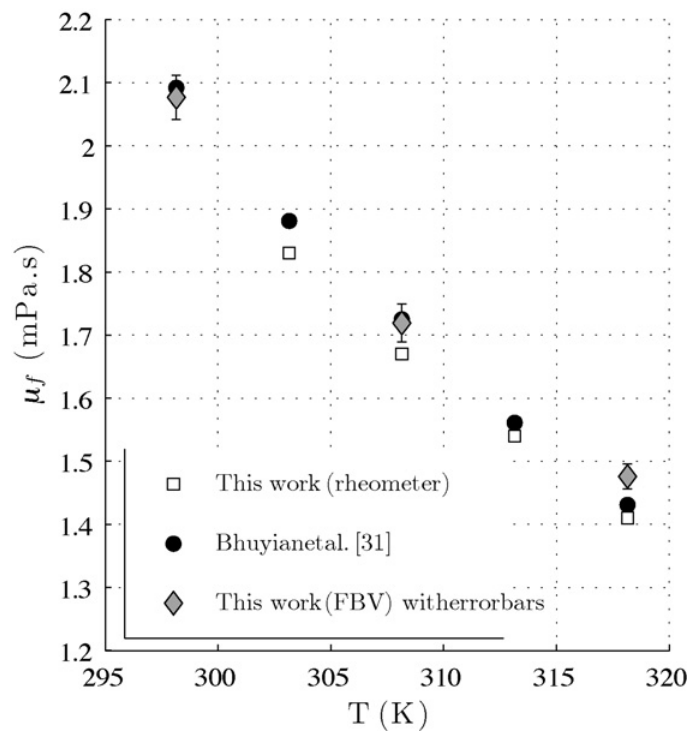

Fig. 4. Viscosity of pure DMSO as a function of temperature. Comparison of the falling ball viscometer (FBV) with literature data and rheometer measurements at atmospheric pressure.

range that could be explored for the binary $\mathrm{CO}_{2}$-cocoa butter. This is however not true for viscosity for which no values neither for DMSO under pressurized $\mathrm{CO}_{2}$ nor for the other candidates could be found. Furthermore, since the apparatus has been designed to operate under $\mathrm{CO}_{2}$ pressure, which has especially no effect on the size of both the glass tube and the aluminium ball, atmospheric comparative measurements could be chosen to validate the technique.

The experimental technique has been validated at atmospheric pressure by comparing the viscosities of pure DMSO at 298.15, 308.15 and $318.15 \mathrm{~K}$ with literature data [31] and with rheometer measurements (Fig. 4) done with a dynamic rotational rheometer (Haake Rheostress 600, Thermo electron, Germany) with coneplate geometry ( $1^{\circ}$ angle cone and $60 \mathrm{~mm}$ diameter). Shear stress was recorded according to shear rate, which was varied from 300 to $1000 \mathrm{~s}^{-1}$, at a fixed temperature. Fig. 4 shows that validation measurements with pure DMSO are in good agreement with the literature and the standard rheological measurements. Moreover, whatever the temperature, measurements with the rotational rheometer have shown a linear evolution of shear stress according to shear rate and the correlation coefficient remains higher than 0.9992 . These measurements validate the assumption of a Newtonian behaviour of DMSO.

In addition, $\mathrm{CB}$ viscosity was measured with the falling ball viscometer for temperatures from 313.15 to $353.15 \mathrm{~K}$ and at atmospheric pressure (Table 2 ). The results obtained were compared with literature data [13] and rheological measurements (Fig. 5). The latter have shown again a linear evolution of shear stress according to shear rate whatever the temperature. Correlation coefficient remains higher than 0.9999 . CB is then a Newtonian fluid. Moreover, the logarithm of the viscosity increases linearly with the

Table 2

Operating parameters, velocity and density measurements and viscosity of liquid cocoa butter by falling ball viscometry at atmospheric pressure.

\begin{tabular}{llllll}
\hline$T(\mathrm{~K})$ & $\rho_{f}\left(\mathrm{~kg} \mathrm{~m}^{-3}\right)$ & $v_{b}\left(\mathrm{~mm} \mathrm{~s}^{-1}\right)$ & $\mu_{\text {init }}(\mathrm{mPas})$ & $\mu_{f}(\mathrm{mPas})$ & $\mathrm{Re}$ \\
\hline 313 & 894.97 & 0.39 & 42.20 & $45.38 \pm 0.84$ & 0.8 \\
323 & 888.28 & 0.55 & 30.03 & $32.29 \pm 0.88$ & 1.2 \\
333 & 881.59 & 0.78 & 21.30 & $22.91 \pm 0.83$ & 1.5 \\
343 & 874.90 & 1.03 & 16.25 & $17.54 \pm 1.06$ & 2.17 \\
353 & 868.18 & 1.44 & 11.56 & $12.45 \pm 0.35$ & 2.6 \\
\hline
\end{tabular}




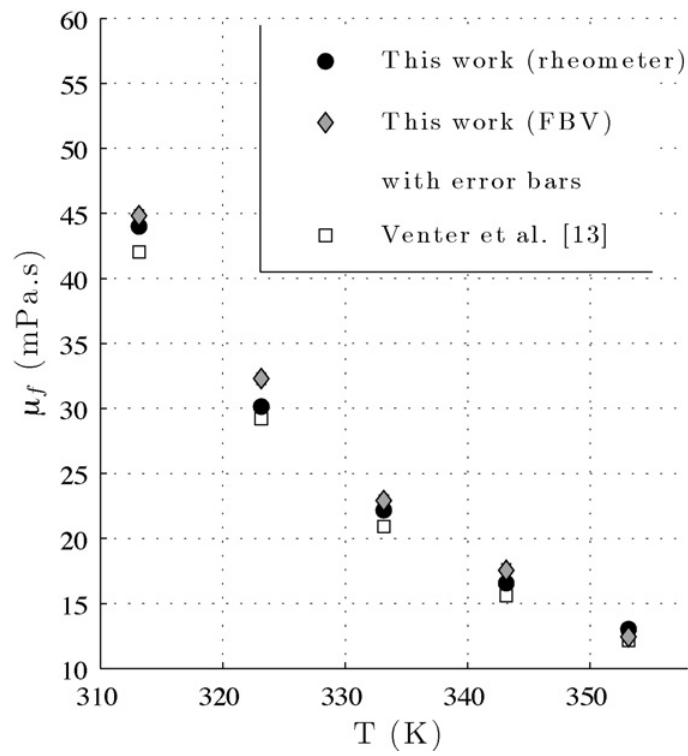

Fig. 5. Viscosity of liquid cocoa butter as a function of temperature. Comparison of the falling ball viscometer (FBV) with literature data and rheometer measurements at atmospheric pressure.

reciprocal temperature. As reminded by Peter and Jakob [32], the corresponding slope is proportional to the activation energy for the change in molecular structure. Considering that CB could be represented by one molecule as a pseudo-component, the deduced activation energy is $27.94 \mathrm{~kJ} / \mathrm{mol}$. Fig. 5 shows that all measurements are in agreement. Hence, it confirms that the falling ball viscometer is a reliable technique.

\section{Results and discussion}

\subsection{Results obtained for $\mathrm{CO}_{2}$-saturated cocoa butter}

Viscosities were measured for $\mathrm{scCO}_{2}$-saturated $\mathrm{CB}$ mixture for pressures ranging from 0.1 to $25 \mathrm{MPa}$ at 313.15 and $353.15 \mathrm{~K}$ and compared to the results of Venter et al. [13] who performed viscosity measurements using a vibrating quartz viscometer (Figs. 6 and 7).

It can be seen that the viscosity decreases drastically with pressure in a first step. This behaviour has been already observed for binary mixtures [33]. The magnitude of this decrease is $93 \%$ at $313.15 \mathrm{~K}$ and $85 \%$ at $353.15 \mathrm{~K}$. This can be seen in Fig. 8 , where the viscosity is plotted against the pressure but also against the $\mathrm{CO}_{2}$ solubility in cocoa butter. These solubility values have been obtained in previous experiments and are expressed in mass fraction [28]. The maximal viscosity reduction is reached at approximately $15 \mathrm{MPa}$ as observed by Venter et al. [13]. This viscosity decrease can be attributed to the increasing $\mathrm{CO}_{2}$ dissolution into the melted media with the pressure (Fig. 8) - this effect being amplified at $313.15 \mathrm{~K}$ because of a higher $\mathrm{CO}_{2}$ dissolution at this lower temperature. Beyond $10 \mathrm{MPa}$, the drop in viscosity slows down and eventually no longer evolves above $15 \mathrm{MPa}$. This is the reason why the two viscosity curves become closer with the rise in pressure and finally almost identical above $15 \mathrm{MPa}$. In other words, at pressures below $15 \mathrm{MPa}$ the $\mathrm{CO}_{2}$ dissolution governs the viscosity decrease, whereas at higher pressures, this effect may be counterbalanced by the effect of hydrostatic pressure. The effect of $\mathrm{CO}_{2}$ dissolution in fats on several thermodynamic properties has already been documented, for instance on melting temperature which diminishes at high pressures [34]. It is also noticeable that, as a consequence of the above interpretation at the highest $\mathrm{CO}_{2}$ dissolution levels,

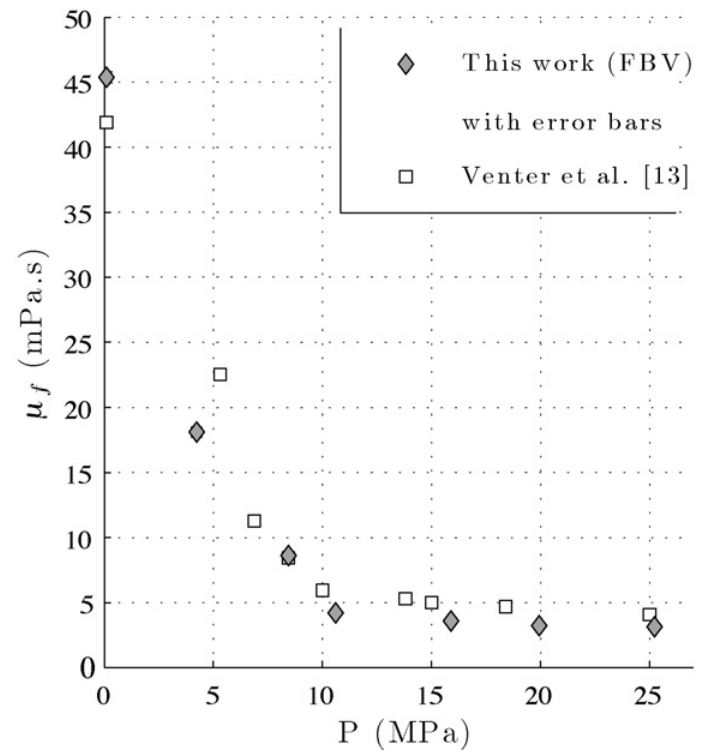

Fig. 6. Viscosity of $\mathrm{CO}_{2}$-saturated cocoa butter as a function of pressure at $313.15 \mathrm{~K}$.

the temperature effect on viscosity is far less significant. However, the above interpretation cannot be generalized because the mixture behaviour highly depends on interactions between molecules, which may differ according to the chain length and double bonds number of the fatty acids [32].

As for literature results, Venter et al. used the vibrating quartz technology [13]. It involves the torsional vibration of a cylindrical crystal and can be used in a wide range of viscosities, between 0.01 and $10^{4} \mathrm{mPa}$ s [13]. The viscous forces exerted by the fluid modify the resonance frequency of the submerged quartz crystal. The signal processing enables to deduce the fluid viscosity from intrinsic characteristics of the crystal (mass and surface). This technology appears to be a straighter method for viscosity determination than the falling ball viscometer. However, no information is given concerning the need for calibration and the calculation assumptions: the limits and the reliability of this technique are unknown.

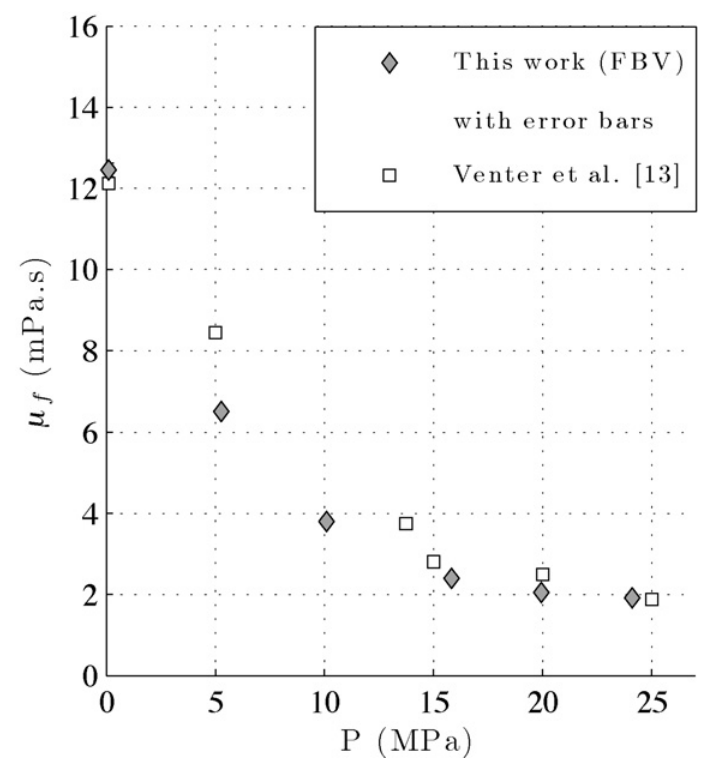

Fig. 7. Viscosity of $\mathrm{CO}_{2}$-saturated cocoa butter as a function of pressure at $353.15 \mathrm{~K}$. 

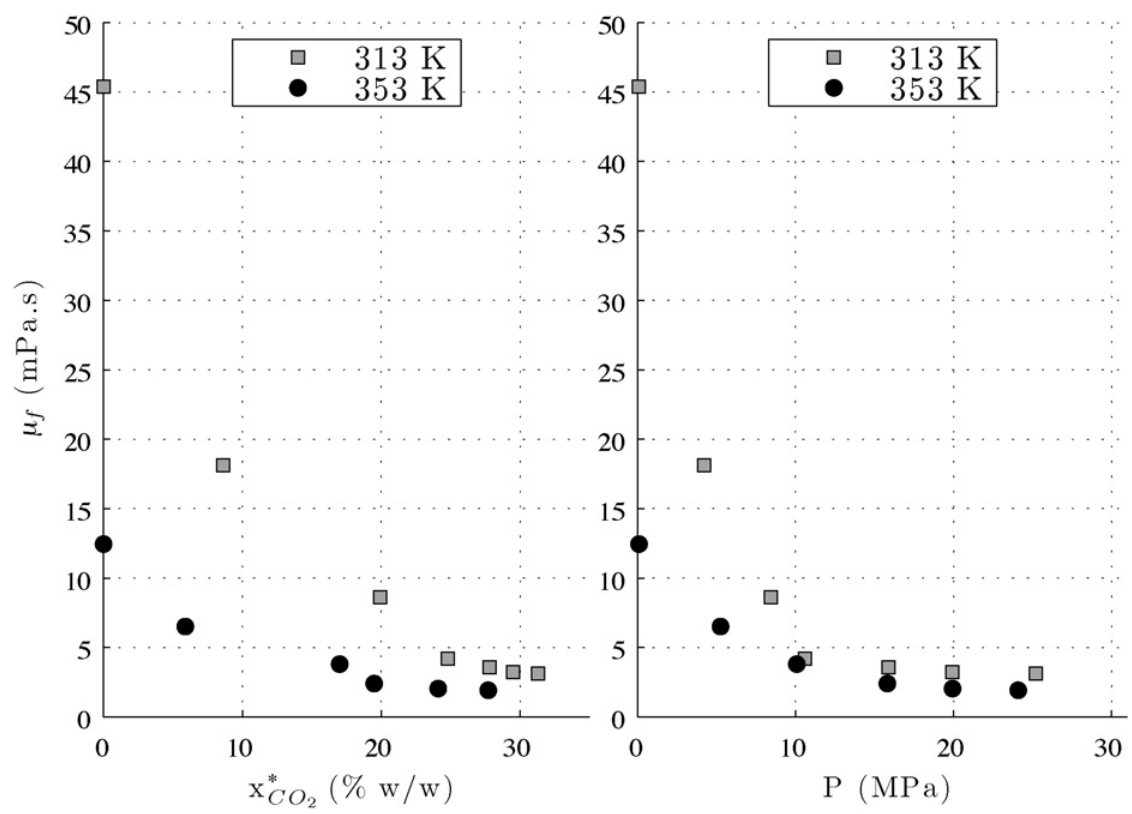

Fig. 8. Viscosity of $\mathrm{CO}_{2}$-saturated cocoa butter as a function of $\mathrm{CO}_{2}$ solubility (ref. [28]) and pressure.

Table 3

Viscosity of $\mathrm{CO}_{2}$-saturated cocoa butter by falling ball viscometry at $313 \mathrm{~K}$.

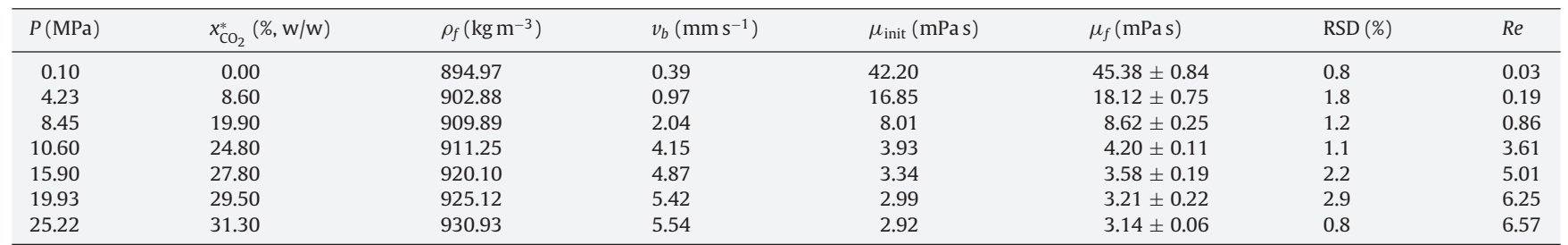

Concerning the falling ball viscometer, it requires (i) the terminal velocity, (ii) the fluid density and (iii) a CFD simulation. Measurements have been repeated thrice: each one implies one set of five falling ball velocity measurements, which are performed with a single loading of the autoclave. A good precision ( $\pm 3 \%$ ) and a good reproducibility with relative standard deviation(RSD) ranging between $0.3 \%$ and $2.9 \%$ (Tables 3 and 4 ) have been obtained:

$\mathrm{RSD}=100 \frac{\sqrt{\frac{1}{N} \sum_{i=1}^{i=N}\left(\mu_{f_{i}}-\bar{\mu}_{f}\right)^{2}}}{\bar{\mu}_{f}}$

Fig. 9 displays the magnification of the CFD simulation results nearby the ball. This simulation uses the experimental conditions given in the last line of Table 3. The color plot represents isovelocity values and the velocity field is materialized by arrow plots at three different depths: $z=-\mathrm{Rb}, \mathrm{Rb}, 2 \mathrm{Rb}$. The velocity profiles at different distances from the ball are shown in Fig. 10. The fluid flow, one ball radius away from the ball, is already similar to the theoretical Poiseuille flow. Furthermore, the mean velocity of the fluid, constant all along the tube, is not far from the corrected value. In addition, the relative average deviation of the viscosity between the CFD and the initialization model, defined by Eq. (4), is close to $7 \%$ for all temperatures. This is another evidence that the equipment characteristics have not been modified by the change in temperature.

3.2. Discussion on the falling ball viscometer technique: benefits and limitations

The main assets of this FBV technique are as follows.

The FBV does not require any calibration. Indeed, there is no need to determine a constant including several physical parameters linked to the apparatus or to operating conditions such as temperature. All these parameters are explicitly taken into account in the CFD model. In addition, wall and ends effects are intrinsic to the CFD model: the mesh is refined enough in the restricted region between the ball and the inner tube to take them into account.

Table 4

Viscosity of $\mathrm{CO}_{2}$-saturated cocoa butter by falling ball viscometry at $353 \mathrm{~K}$.

\begin{tabular}{|c|c|c|c|c|c|c|c|}
\hline$P(\mathrm{MPa})$ & $x_{\mathrm{CO}_{2}}^{*}(\%, \mathrm{w} / \mathrm{w})$ & $\rho_{f}\left(\mathrm{~kg} \mathrm{~m}^{-3}\right)$ & $v_{b}\left(\mathrm{~mm} \mathrm{~s}^{-1}\right)$ & $\mu_{\text {init }}(\mathrm{mPas})$ & $\mu_{f}(\mathrm{mPa})$ & RSD (\%) & $R e$ \\
\hline 0.10 & 0,00 & 868.18 & 1.44 & 11.58 & $12.45 \pm 0.35$ & 1.3 & 0.40 \\
\hline 5.26 & 5.90 & 873.05 & 2.76 & 6.05 & $6.51 \pm 0.16$ & 1.0 & 1.48 \\
\hline 10.09 & 17.00 & 876.89 & 4.71 & 3.53 & $3.80 \pm 0.15$ & 1.7 & 4.35 \\
\hline 15.82 & 19.50 & 883.15 & 7.45 & 2.23 & $2.40 \pm 0.03$ & 0.5 & 10.98 \\
\hline 19.94 & 24.10 & 884.14 & 8.70 & 1.91 & $2.05 \pm 0.02$ & 0.4 & 15.03 \\
\hline 24.10 & 27.70 & 887.72 & 9.27 & 1.79 & $1.92 \pm 0.03$ & 0.3 & 17.14 \\
\hline
\end{tabular}




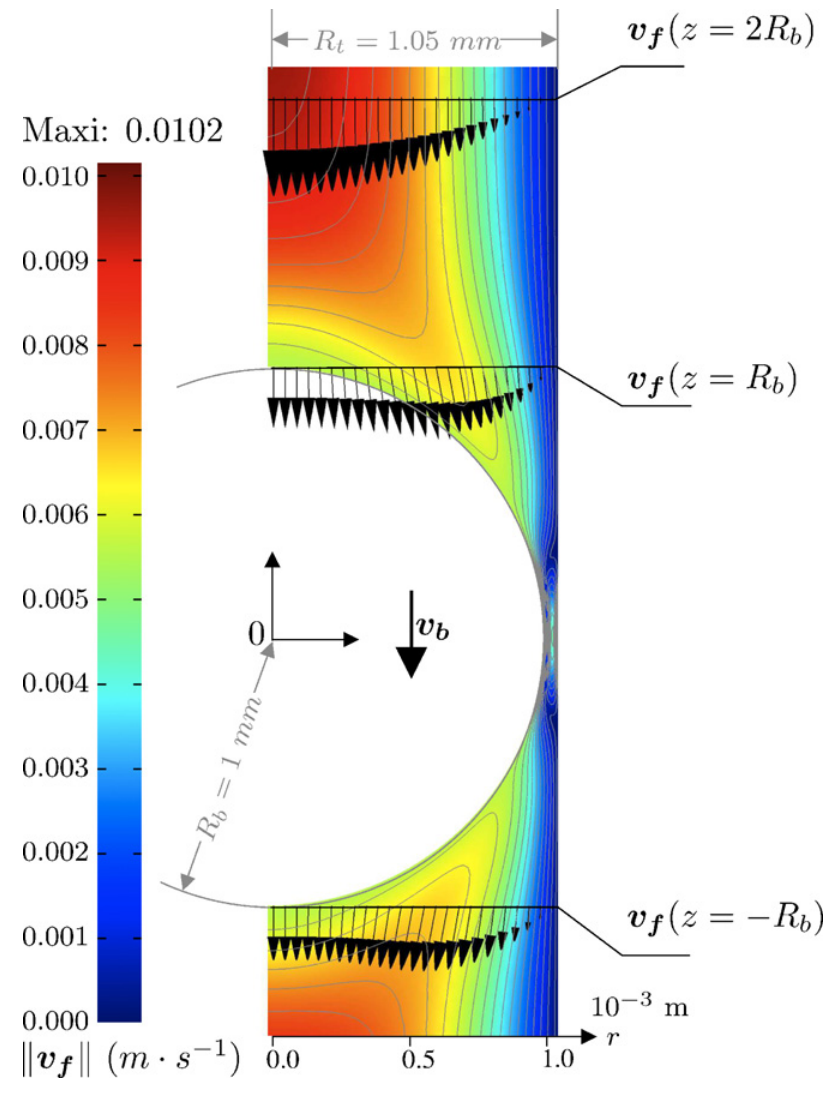

Fig. 9. Magnification of the result of CFD simulation using the operating conditions of the Table 3 at $P=25.22 \mathrm{MPa}$. Isovelocities (color plot) and velocity field (arrow plots) at $z=-\mathrm{Rb}, \mathrm{Rb}, 2 \mathrm{Rb}$.

The technique proposed is based on the falling of a ball through a tube opened at both ends with a diameter slightly greater than that of the balls. Hence, there is no upflow of liquid from beneath the ball as it is falling. This induces a simplified model compared to the case of a tube closed at the bottom end. In particular, the tube is long enough (tube length to radius ratio is 200) to allow considering a fixed mesh in the referential frame of the ball with a moving inner tube wall.

Sizes of the tube and of the ball have been chosen so that the flow remains laminar, stationary and axial symmetric. For a ball

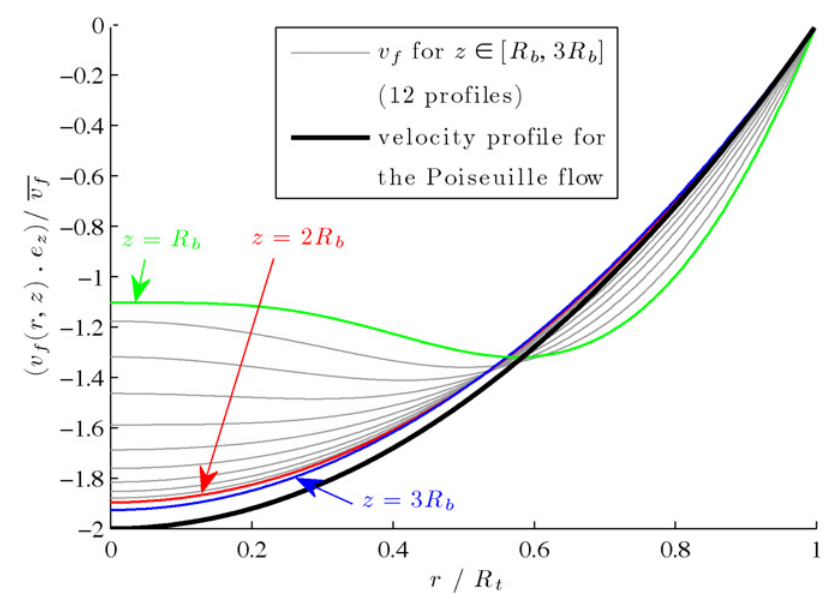

Fig. 10. Comparison between the velocity profiles at different distances from the ball and the Poiseuille's profile.

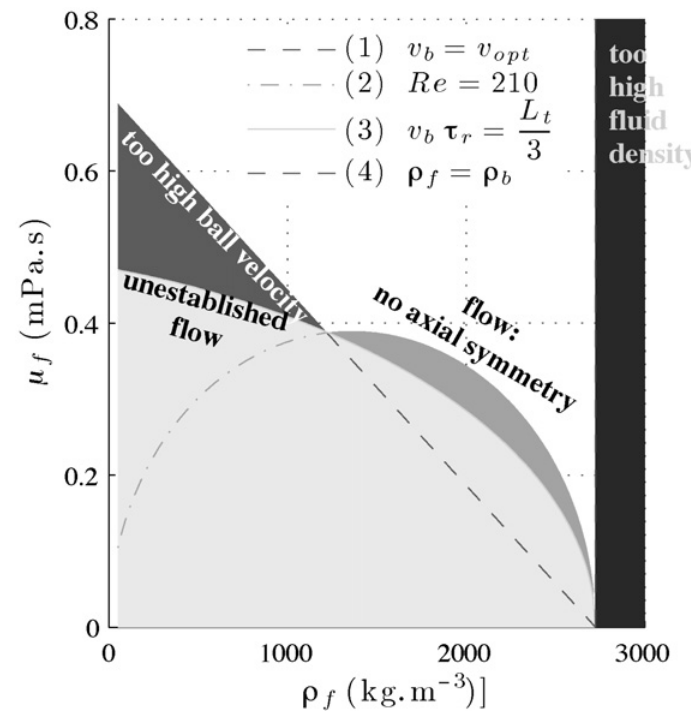

Fig. 11. The four operating limitations of the falling ball viscometer.

falling in an infinite medium, this flow features correspond to a Reynolds number lower than 210 . For a confined flow, as in the present case, this number is greater, but nevertheless the value of 210 has been considered. Hence, CFD modelling can be performed in two-dimensional and axial symmetric space. This induces a limited number of elements for the mesh (15,000 rather than $2.10^{6}$ for a three-dimensional space) and then a reduced calculating time (around $10 \mathrm{~min}$ for each experiment). Furthermore, the viscosity value deduced from the initialization model, which is used as a guessed-value in the CFD calculation, is accurate enough to allow a timesaving calculation.

An investigation of the limits inherent to this technique has been achieved: maximal terminal velocity for our optical device, stationary, laminar and axial symmetric flow limitation $(R e<210)$ and terminal velocity not reached yet at the visualization height.

First, the criteria for the optical limit are the minimal number of images giving a precise value of speed, which is 100 , and sufficient image sharpness. As our camera capture speed is $500 \mathrm{fps}$ and the visual height is $7 \mathrm{~mm}$, the maximal velocity of the falling ball is $v_{\mathrm{opt}}=35 \mathrm{~mm} \mathrm{~s}^{-1}$. In terms of viscosity value, given by Eq. (4), and considering Reynolds number, given by Eq. (A.13), this limitation becomes:

$\mu_{f} \geq \frac{1}{6} \frac{\left(\rho_{b}-\rho_{f}\right) g R_{b} R_{t}^{2}}{v_{\mathrm{opt}} L_{t}}$

The fluid viscosity and density domain for which the measurements cannot be performed with the falling ball viscometer for aluminium balls of $2 \mathrm{~mm}$ diameter is represented by the curve (1) in Fig. 11.

This optical device implies that the medium be transparent. It is an obvious drawback of this technique but it could be overcome by changing the detection device. In fact, an electromagnetic detection device is being studied. This kind of device has already been used in opaque media such as vegetable oil [17] or hydrocarbon mixtures [16].

Second, the model hypotheses, axial symmetry and stationary flow, require to maintain the Reynolds number below $R e_{\max }=210$. This leads to the second limit (curve (2) in Fig. 11):

$\mu_{f} \geq \sqrt{\frac{1}{3} \frac{\left(\rho_{b}-\rho_{f}\right) \rho_{f} g R_{b}^{3} R_{t}}{R e_{\max } L_{t}}}$ 
Third, the flow has to be stationary at the visualization height $L_{t} / 2$. Therefore, by considering a safety margin:

$v_{b} \tau_{r} \leq \frac{L_{t}}{3}$

with:

$\tau_{r}=\frac{\left(2 \rho_{b}+\rho_{f}\right) R_{b}^{2}}{9 \mu_{f}}$

where $R_{b}$ is the ball radius, $\mu_{f}$ is the fluid viscosity and $\rho_{f}$ and $\rho_{b}$ are respectively the fluid and ball densities.

Eq. (15) gives the classical relaxation time $\tau_{r}$ [35], which is the time for a ball to reach its terminal velocity in an infinite medium at low Reynolds number $(R e<210)$. Together with Eqs. (4) and (14), this relation leads to the third limit for the viscosity (curve (3) in Fig. 11):

$\mu_{f} \geq \frac{1}{3} \frac{R_{t}}{L_{t}} \sqrt{\left(\rho_{b}-\rho_{f}\right)\left(\rho_{b}+\frac{1}{2} \rho_{f}\right) g R_{b}^{3}}$

The fourth and last limit concerns the ball material: its density has to be greater than that of the fluid (curve (4) in Fig. 11). In addition, it has to be non-dilatable and the $\mathrm{ScCO}_{2}$ must not dissolve into it.

Anyway, this viscometer can be used in a wide range of viscosities. For high levels of viscosity, the falling ball time may be long but changing the ball material for a denser one could reduce it.

Finally, for aluminium balls, the two first limits are the most restrictive and it can be seen in Eqs. (12) and (13) that the greater the ball density and radius, the more reduced the operating domain.

\section{Conclusion}

A falling ball viscometer has been designed to perform viscosity measurements of a liquid phase. This technique can be applied at high pressure to any liquid in equilibrium with a vapour phase.

The original feature of this falling ball viscometer technique consists of a tube opened at both ends. This specificity enables a first viscosity expression (the initialization model) that does not require any adjustable parameter and gives satisfying viscosity estimation. Second, CFD modelling and simulation performed for an accurate viscosity determination are simplified and shortened. This technique requires either the knowledge or an assumption of the rheological behaviour of the fluid. Molten cocoa butter behaving as a Newtonian fluid, the hypothesis of the same rheological behaviour under pressure was made. As in all velocity-based measurement of viscosity, this technique also requires the knowledge of the fluid density.

This viscometer has been validated at atmospheric pressure with DMSO and cocoa butter at 298.15, 308.15 and 318.15 K. Comparative measurements with literature data have been achieved on cocoa butter saturated with $\mathrm{CO}_{2}$, at 313.15 and $353.15 \mathrm{~K}$ and between 0.1 and $25 \mathrm{MPa}$. All the measurements are in good agreement with literature results obtained with a cocoa butter from the same manufacturer but with a different technique.

For both isotherms tested, in the range $0-15 \mathrm{MPa}$, results show that, the higher the $\mathrm{CO}_{2}$ dissolution in the cocoa butter, the lower the viscosity. The viscosity no longer evolves beyond $15 \mathrm{MPa}$. The maximal relative decrease in viscosity is $93 \%$ at $313.15 \mathrm{~K}$ and $85 \%$ at $353.15 \mathrm{~K}$. The drop in viscosity is more pronounced at $313.15 \mathrm{~K}$ because of the greater $\mathrm{CO}_{2}$ dissolution. The viscosity of both isotherms becomes closer and almost identical beyond $15 \mathrm{MPa}$. The lowest values are $1.9 \mathrm{mPa} s$ at $313.15 \mathrm{~K}$ and $3.1 \mathrm{mPas}$ at $353.15 \mathrm{~K}$. At the highest $\mathrm{CO}_{2}$ dissolution levels, the temperature effect is therefore minimised. In addition, at pressures below $15 \mathrm{MPa}$ the $\mathrm{CO}_{2}$ dissolution governs the viscosity decrease, whereas at higher pressures, this effect may be counterbalanced by the effect of hydrostatic pressure and viscosity no longer evolves.

Given the good reliability of the technique, its implementation in other systems such as organic solvent- $\mathrm{CO}_{2}[25]$ polymer- $\mathrm{CO}_{2}[8]$ and ionic liquid- $-\mathrm{CO}_{2}$ is under investigation.

The limitations of the technique have also been evidenced. The device enabled viscosity measurements down to $0.4 \mathrm{mPa}$ s, due to the operating conditions and to the flow regime that has been modelled, which must be laminar, axial symmetric and stationary. This value is strongly dependent on the radii of the ball and the tube, and on the ball density. In addition, for fluids whose density is lower than $1200 \mathrm{~kg} \mathrm{~m}^{-3}$, the prevailing limitation is the ball velocity, which has to be lower than $35 \mathrm{~mm} \mathrm{~s}^{-1}$. This is due to the optical device and could be easily overcome by changing this device by a camera with higher resolution and speed. Obviously this technique is also restricted to transparent media. To extend it to opaque media, the velocity measurement device should be changed.

\section{Acknowledgements}

The authors would like to acknowledge the financial support of CNRS (France-Project PEPS07_33) and the Institut Carnot M.I.N.E.S. (France). Gerkens Cacao (The Netherlands) is gratefully acknowledged for supplying the cocoa butter. The laboratory UMR-CNRS 8612 of the University of Paris-Sud (France) is also gratefully acknowledged for the composition analysis of cocoa butter.

\section{Appendix A.}

The forces exerted on the fluid flowing through the volume $V_{f}$ (hatched part in Fig. 12) of surface $S_{f}$ are the pressure force, the gravity force and the viscous friction force.

When the ball reaches its terminal velocity, the flow is stationary and the momentum balance expression is:

$\int_{S_{f}} \rho_{f} \boldsymbol{v}_{f}\left(\boldsymbol{v}_{f} \cdot \boldsymbol{n}\right) d S=\int_{S_{f}}-P \boldsymbol{n} d S+\int_{V_{f}} \rho_{f} \mathbf{g} d V+\int_{S_{f}} \boldsymbol{\sigma}_{V} \cdot \boldsymbol{n} d S$

where the surface $S_{f}$ of the considered system splits into four domains shown in Fig. 12:

$S_{f}=S_{i} \cup S_{0} \cup S_{t} \cup S_{b}$

Since the flow is stationary, the terms $\boldsymbol{v}_{f} \cdot \boldsymbol{n}$ on $S_{i}$ and $\boldsymbol{v}_{f} \cdot \boldsymbol{n}$ on $S_{o}$ are presumed to be opposite. Furthermore, $v_{f}$ is null on $S_{t}$. Lastly, as the ball does not roll, the velocity of the fluid on the surface $S_{b}$ is constant and equal to $-v_{b} \boldsymbol{e}_{z}$. So, in Eq. (A.1), the first term corresponding to the "in-out" momentum balance is null according to the Gauss' theorem:

$$
\begin{aligned}
\int_{S} \rho_{f} \boldsymbol{v}(\boldsymbol{v} \cdot \boldsymbol{n}) d S & =\int_{S_{b}}\left(-\rho_{f} v_{b} \boldsymbol{e}_{z}\right)\left(-v_{b} \boldsymbol{e}_{z} \cdot \boldsymbol{n}\right) d S \\
& =\rho_{f} v_{b}^{2}\left(\boldsymbol{e}_{z} \cdot \int_{S_{b}} \boldsymbol{n} d S\right) \boldsymbol{e}_{z}=0
\end{aligned}
$$

In the same way, the second term in Eq. (A.1) splits into four terms on each surface. The resultant force of the terms on $S_{i}$ and $S_{0}$ corresponds to the hydrostatic pressure force assuming that the fluid is nearly motionless outside the tube. On $S_{t}$ the resultant force is null because of the axial symmetry hypothesis. So this pressure force balance becomes:

$\int_{S}-P \boldsymbol{n} d S=\left(\rho_{f} g L_{t}\right)\left(\pi R_{t}^{2}\right) \boldsymbol{e}_{z}-\boldsymbol{F}_{f / b}^{(P)}=\rho_{f} g V_{t} \boldsymbol{e}_{z}-\boldsymbol{F}_{f / b}^{(P)}$

where $\boldsymbol{F}_{f / b}^{(P)}$ is the pressure force that the fluid exerts on the ball. 


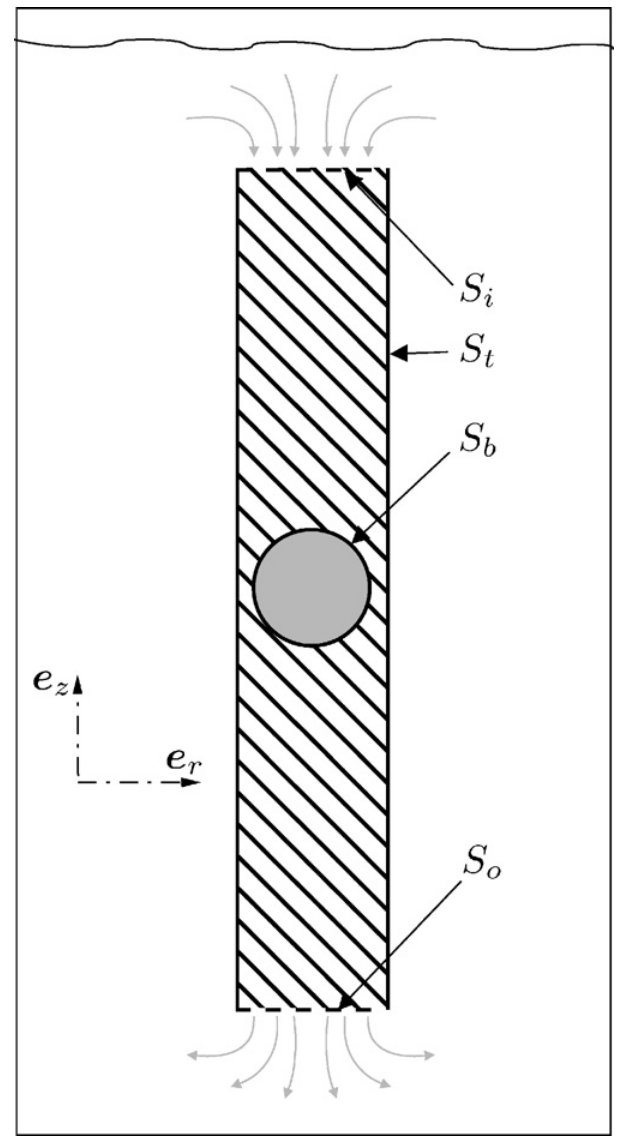

Fig. 12. The system (hatched area) for the initialization falling ball model.

The third term in Eq. (A.1) corresponds to the gravity forces:

$\int_{V_{f}} \rho_{f} \mathbf{g} d V=-\rho_{f} g \boldsymbol{e}_{z}\left(V_{t}-V_{b}\right)$

The last term in Eq. (A.1) corresponds to the viscous force:

$\int_{S_{f}} \boldsymbol{\sigma}_{V} \cdot \boldsymbol{n} d S=\int_{S_{i}} \boldsymbol{\sigma}_{V} \cdot \boldsymbol{e}_{z} d S-\int_{S_{o}} \boldsymbol{\sigma}_{V} \cdot \boldsymbol{e}_{z} d S-\boldsymbol{F}_{f / t}^{(V)}-\boldsymbol{F}_{f / b}^{(V)}$

The integrals of $\boldsymbol{\sigma}_{V} \cdot \boldsymbol{n}$ on the domain $S_{i}$ and $S_{o}$ are assumed to be opposite. This could be demonstrated in the case of a Newtonian fluid (Eq. (6)) since it has been already supposed that $v_{f} \cdot \boldsymbol{n}$ on $S_{i}$ and on $S_{o}$ are opposite.

Thus, after simplifications, the Eq. (A.1) of the momentum balance for the fluid is reduced to:

$\rho_{f} g V_{b} \boldsymbol{e}_{z}-\boldsymbol{F}_{f / b}^{(T)}-\boldsymbol{F}_{f / t}^{(V)}=0$

According to the fundamental principle of dynamics applied to a ball that falls at constant velocity without rolling:

$\rho_{b} g V_{b} \boldsymbol{e}_{z}=\boldsymbol{F}_{f / b}^{(T)}$

Thus, the combination of Eqs. (A.8) and (A.9) leads to:

$\boldsymbol{F}_{f / t}^{(V)}=-\left(\rho_{b}-\rho_{f}\right) g V_{b} \boldsymbol{e}_{z}$

In addition the viscous resultant force that the fluid exerts on the tube is linked to the definition of the friction factor $f$ of flow in circular tubes:

$\left\|\boldsymbol{F}_{f / t}^{(V)}\right\|=\left(2 \pi R_{t} L_{t}\right)\left(\frac{1}{2} \rho_{f} \bar{v}_{f}^{2}\right) f$
Given that the ball diameter $(2 \mathrm{~mm})$ is negligible compared to the tube length $(0.2 \mathrm{~m}) \mathrm{Eq}$. (A.11) applies all along the tube. The Poiseuille laminar flow implies that the friction factor is linked to the Reynolds number according to the following correlation:

$f=\frac{16}{R e}$

with:

$R e=\frac{2 \rho_{f} R_{t} \bar{v}_{f}}{\mu_{f}}$

The mean flow rate, far from the ball, is assumed to be the same as the flow rate of the fluid pushed by the falling ball acting as a piston:

$\rho_{f} \bar{v}_{f}\left(\pi R_{t}^{2}\right)=\rho_{f} v_{b}\left(\pi R_{b}^{2}\right)$

Thus, after simplifications, Eqs. (A.10)-(A.14) lead to:

$\mu_{f}=\frac{1}{6} \frac{\left(\rho_{b}-\rho_{f}\right) g R_{b} R_{t}^{2}}{L_{t} v_{b}}$

\section{References}

[1] A. Bertucco, G. Vetter, High Pressure Technology: Fundamentals and Applications, Elsevier, Oxford, 2001.

[2] M. Sauceau, J. Fages, J.-J. Letourneau, D. Richon, A novel apparatus for accurate measurements of solid solubilities in supercritical phases, Industrial and Engineering Chemistry Research 39 (2000) 4609-4614.

[3] M.Sauceau, J.-J. Letourneau, D. Richon, J. Fages, Enhanced density-based models for solid compound solubilities in supercritical carbon dioxide with cosolvents, Fluid Phase Equilibria 208 (2003) 99-113.

[4] M.E. Yener, P. Kashulines, S.S.H. Rizvi, P. Harriott, Viscosity measurements and modelling of lipid-supercritical carbon dioxide mixtures, Journal of Supercritical Fluids 11 (1998) 151-162.

[5] M. Sauceau, C. Nikitine, E. Rodier, J. Fages, Effect of supercritical carbon dioxide on polystyrene extrusion, Journal of Supercritical Fluids 43 (2007) 367-373.

[6] D.L. Tomasko, A. Burley, L. Feng, S.-K. Yeh, K. Miyazono, S. Nirmal-Kumar, I. Kusaka, K. Koelling, Development of $\mathrm{CO}_{2}$ for polymer foam applications, Journal of Supercritical Fluids 47 (2009) 493-499.

[7] E. Reverchon, R. Adami, S. Cardea, G. Della Porta, Supercritical fluids processing of polymers for pharmaceutical and medical applications, Journal of Supercritical Fluids 47 (2009) 484-492.

[8] F. Cansell, C. Aymonier, Design of functional nanostructured materials using supercritical fluids, Journal of Supercritical Fluids 47 (2009) 508-516.

[9] K. Jacobsen, D. Pierick, Injection molding innovation: the microcellular foam process, Plastics Engineering 57 (2001) 46-51.

[10] M. Nobelen, S. Hoppe, C. Fonteix, F. Pla, M. Dupire, B. Jacques, Modeling of rheological behavior of polyethylene/supercritical $\mathrm{CO}_{2}$ solutions, Chemical Engineering Science 61 (2006) 5334-5345.

[11] P. Kashulines, S.S.H. Rizvi, P. Harriott, J.A. Zollweg, Viscosities of fatty acids and methylated fatty acids saturated with supercritical carbon dioxide, Journal of American Oil Chemists Society 68 (1991) 912-921.

[12] D. Gourgouillon, H.M.N.T. Avelino, J.M.N.A. Fareleira, M. Nunes da Ponte, Simultaneous viscosity and density measurement of supercritical $\mathrm{CO}_{2}$-saturated PEG 400, Journal of Supercritical Fluids 13 (1998) 177-185.

[13] M.J. Venter, P. Willems, S. Kareth, E. Weidner, N.J.M. Kuipers, A.B. De Haan, Phase equilibria and physical properties of $\mathrm{CO}_{2}$ saturated cocoa butter mixtures at elevated pressures, Journal of Supercritical Fluids 41 (2007) 195-203.

[14] R. Mertsch, B.A. Wolf, Viscosity and mixing behavior of the system ethylenepolyisobutene, Journal of Supercritical Fluids 7 (1994) 165-169.

[15] P. Daugé, A. Baylaucq, L. Marlin, C. Boned, Development of an isobaric transfer viscometer operating up to $150 \mathrm{MPa}$. Application to the methane + decane mixture, Journal of Chemical and Engineering Data 46 (2001) 823-830.

[16] C. Boned, C.K. Zéberg-Mikkelsen, A. Baylaucq, P. Daugé, High-pressure dynamic viscosity and density of two synthetic hydrocarbon mixtures representative of some heavy petroleum distillation cuts, Fluid Phase Equilibria 212 (2003) 143-164.

[17] C.J. Schaschke, S. Allio, E. Holmberg, Viscosity measurement of vegetable oil at high pressure, Food and Bioproducts Processing 84 (2006) 173-178.

[18] C.J. Schaschke, S. Abid, I. Fletcher, M.J. Heslop, Evaluation of a falling sinkertype viscometer at high pressure using edible oil, Journal of Food Engineering $87(2008) 51-58$

[19] Y.C. Bae, E. Gulari, Viscosity reduction of polymeric liquid by dissolved carbon dioxide, Journal of Applied Polymer Science 63 (1997) 459-466.

[20] K. Liu, F. Schuch, E. Kiran, High-pressure viscosity and density of poly(methyl methacrylate) + acetone and poly(methyl methacrylate) + acetone $+\mathrm{CO}_{2}$ systems, Journal of Supercritical Fluids 39 (2006) 89-101.

[21] S.-D. Yeo, E. Kiran, High-pressure density and viscosity of polystyrene solutions in methylcyclohexane, Journal of Supercritical Fluids 15 (1999) 261-272. 
[22] R. Sih, F. Dehghani, N.R. Foster, Viscosity measurements on gas expanded liquid systems - methanol and carbon dioxide, Journal of Supercritical Fluids 41 (2007) 148-157.

[23] R. Sih, M. Armenti, R. Mammucari, F. Dehghani, N.R. Foster, Viscosity measurements on saturated gas-expanded liquid systems - ethanol and carbon dioxide. Journal of Supercritical Fluids 43 (2008) 460-468.

[24] R. Sih, N.R. Foster, Viscosity measurements on saturated gas expanded liquid systems-acetone and carbon dioxide, Journal of Supercritical Fluids 47 (2008) 233-239.

[25] B. Calvignac, E. Rodier, J.-J. Letourneau, J. Fages, Characterization of thermophysical properties and phase equilibria behaviour of $\mathrm{CO}_{2}$-DMSO mixture, International Journal of Chemical Reactor Engineering 7 (2009) A46.

[26] I. Dee Chang, On the wall effect correction of the stokes drag formula for axially symmetric bodies moving inside a cylindrical tube, Zeitschrift für Angewandte Mathematik und Physik 12 (1961) 6-14.

[27] A. Falade, H. Brenner, Stokes wall effects for particles moving near cylindrica boundaries, Journal of Fluid Mechanics 154 (1985) 145-162.

[28] B. Calvignac, E. Rodier, J-J. Letourneau, J. Fages, Cocoa butter saturated with supercritical carbon dioxide: measurements and modelling of solubility, volumetric expansion, density and viscosity, International Journal of Chemical Reactor Engineering 8 (2010) A73.
[29] J.H Dymond, R. Malhotra, The Tait equation: 100 years on, International Journal of Thermophysics 9 (1988) 941-951.

[30] Comsol Model Gallery, Terminal Falling Velocity of a Sand Grain. Available from: http://www.comsol.fr/showroom/gallery/983/.

[31] M.M.H. Bhuiyan, J. Ferdaush, M.H. Uddin, Densities and viscosities of binary mixtures of $\left\{\right.$ dimethylsulfoxide + aliphatic lower alkanols $\left.\left(C_{1}-C_{3}\right)\right\}$ at temperatures from $T=303.15 \mathrm{~K}$ to $T=323.15 \mathrm{~K}$, Journal of Chemical Thermodynamics 39 (2007) 675-683.

[32] S. Peter, H. Jakob, The rheological behavior of coexisting phases in systems containing fatty acids and dense gases, Journal of Supercritical Fluids 4 (1991) $166-172$.

[33] G. Brunner, Gas Extraction: An Introduction to Fundamentals of Supercritical Fluids and the Application to Separation Processes, Steinkopff, Darmstadt, 1994.

[34] A.R. Sampaio de Sousa, M. Calderone, E. Rodier, J. Fages, C.M.M. Duarte, Solubility of carbon dioxide in three lipid-based biocarriers, Journal of Supercritical Fluids 39 (2006) 13-19.

[35] R. Clift, J.R. Grace, M.E. Weber, Bubbles Drops and Particles, Academic Press, New York/Londres, 1978 